\title{
A TRANSIENT CURRENT MONITORING AND ELECIRODE CHARACTERIZATION SYSTEM FOR A PULSED OYYCIFN ELECTRODE
}

\author{
K. D. WISE \\ Department of Electrical and Compuler Enginecring. The Linicersity of Michigan. \\ -1nn -1rbor, Michigan 15109 ( (j.S.A.) \\ R. B. SMART*a and K. H. MANCY \\ The Encirommentul Chemistry Laboratory. School of l'wblic Ilealth. The Initersity of \\ Hichigan. Alln Arbor, Hichigan lS109 (L.S..1.)
}

(Received 2.1th September 1979)

\section{SUMMIARY}

Non-steady state voltammetry has been applied to membrane electrodes to provide improved sensitivity as well as independence of stirring. This patper describes at new instrumentation system bised on complementary metal sxide-silicon technology for the characterization of a pulsed oxygen electrode. The system provides the necessiary tining, analog-to-digital conversion, and digital display of the transient current.

Dissolved oxygen voltammetric membrane electrodes have found wide use for in-situ determination of oxysen in natural and waste water, biolosical fluids, cells, tissues, and non-aqueous media [1-3]. Most of the systems presently available are based on steady-state measurements. The use of a membrane electrode under continuous polarization, however, has the disadvantage of being operated with the luwest possible sensitivity. Incler these conditions the sensitivity is dependent on the membrane thichess and permeability, as shown by Mancy et al. [2]. The highest sensitivity should be obtained with very thin membranes, but practical considerations limit the membrane thichness to about $2.54 \% 10^{-3} \mathrm{~cm}$. The c:athode area can be increased, but larger electrodes tend to become bulky and gencrally exhibit excessive residial currents. The use of membranes with higher permeability coefficients can also increase the steady-state response. After several years of laboratory and field experience, the main limitations of steady-state electrode systems have been largely due to: (a) lack of long ierm sensitivity, (b) low sensitivity, and (c) the need to maintain a certain amount of mixing at the electrode surface.

apresent address: Department af Chemistry, Hest Vireninia Liniversiiy, Morgantown, Hest Viruniat 26506 , U.S.A. 
The application of a very brief potential pulse to the electrode should make the sensitivity independent of the membrane thickness [2]. The nonsteady state voltammetric technique has been reported by Schmid and Mancy [4], Mancy [5], Lilley et al. [6], and Fowler and Oldham [7]. The use of pulsed potential polarization will increase the electrode sensitivity as well as eliminate the need for constant stirring. A problem associated with the pulsed potential technique is the operational need for more sophisticated and cumbersome electronic equipment than that required for steady-state measurements. The current measurement is often done milliseconds after the pulse application, therefore the measurement must be made with a storage oscilloscope or other fast recording device. The application of the pulse is accompanied by an instantaneous rise of current followed by a decay to the steady-state value. The means for providing accurately timed voltage pulses must also be provided. The instrumentation system described below was developed to provide an accurate technique for electrode characterization by using the pulsed potential method; it also provides higher sensitivity in a portable system for field measurements.

\section{ENPERIMENTAL}

\section{Apparatus}

A YSI (Yellow Springs Instrument Co., Yellow Springs, Ohio) Model 4004 Oxygen Electrode filled with $3.5 \mathrm{M} \mathrm{KCl}$ saturated with $\mathrm{AgCl}$ was used throughout. The membrane was 1 -mil FEP teflon. The area of the platinum cathode was experimentally determined as $9.2 \times 10^{-2} \mathrm{~cm}^{2}[S]$. A Tektronix Type 564 storage oscilloscope (Tektronix, Inc., Beaverton, Oregon) was used to record the transient currents. The electrode was calibrated by using the standard Winkler method [9].

\section{Instrumentation}

The design of the transient current monitoring system was based on the need for independent control over the pulse amplitude, duration, and frequency (interpulse interval). Complementary metal oxide-silicon (CMOS) technology was selected for this application because it provides low power dissipation, relatively high speed, and a high insensitivity to variations in power supply voltage and ambient temperature. The system consists of several sections, as shown in Fig. 1. The voltage to be applied to the electrode is selected by a potentiometer and is continuously variable between zero and $\pm 1.2 \mathrm{~V}$. This electrode voltage is buffered and applied to the working electrode through a series electronic switch. For three-electrode systems, the reference electrode potential is added to the selected electrode voltage to eliminate the effects of polarization at the anode. An FET-input operational amplifier is used as a non-inverting buffer, to ensure a reference electrode current of less than $20 \mathrm{pA}$. A second FET-input amplifier senses the current passed by the working electrode and converts it to a voltage with an output 


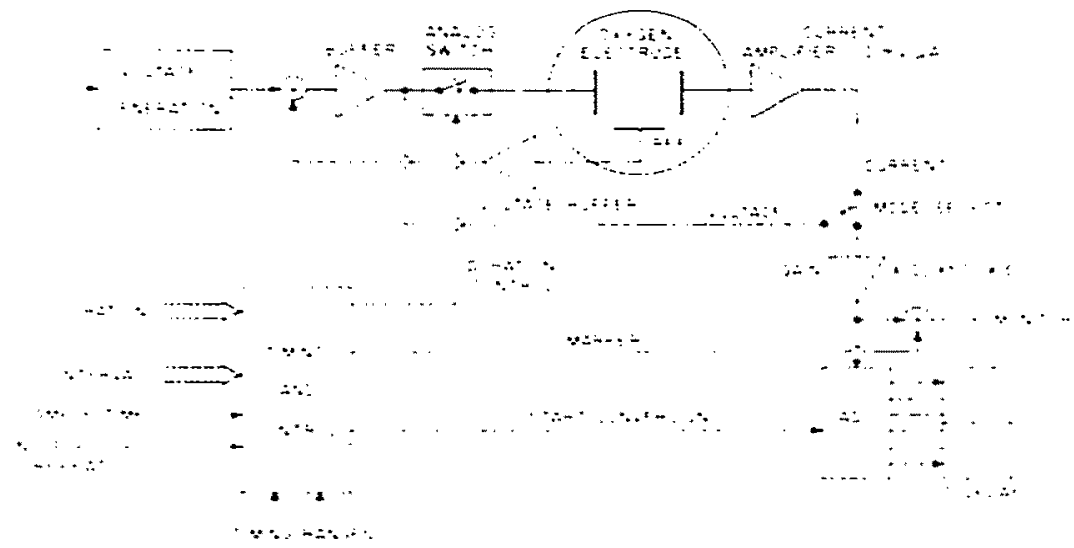

Fig. 1. Schematic of transient current monitoring electrode characterization șstem.

of $10 \mathrm{mV} \mu \mathrm{A}^{-1}$. Subsequent amplifiers allow the user to select overall amplifications of $0.1 \mathrm{~V} \mu \mathrm{A}^{-1}, 0.5 \mathrm{~V} \mu_{-1} \mathrm{~A}^{-1}$, or $1 V \mu \mathrm{A}^{-1}$. The resulting signal is available for display on an oscilloscope via a connector on the back of the chassis. The amplification section has a frequency response from d.c. to about $10 \mathrm{kHz}$.

The pulse duration and interpulse interval are determined by the timing and control section. These parameters are selected by sixtcen toggle switches on the front panel, eight of which are used for each parameter. These switches are binarily weighted and are used to preset eight-bit binary counters which are driven by a crystal-senerated clock signal. The clock can be adjusted at $1 \mathrm{~ms}$ or $10 \mathrm{~ms}$ for pulse duration and at $10 \mathrm{~ms}$ or $100 \mathrm{~ms}$ for pulse interval. The resulting parameter ranges are selectable from $1 \mathrm{~ms}$ to $2.55 \mathrm{~s}$ for duration and $10 \mathrm{~ms}$ to $25 . \overline{5} \mathrm{~s}$ for interval. The pulses may be applied repetitively or individually (single pulse) via front panel switches. These timing intervals are accurate to within $0.3 \%$ or better and are stable to within $₫ 20 \mathrm{ppm}$ over the ambient temperature range from $10^{\circ} \mathrm{C}$ to $40^{\circ} \mathrm{C}$.

The sample time on the present system is continuously variable between $5 \mathrm{~ms}$ and about $1.5 \mathrm{~s}$ in two overlapping ranges which are automatically switched with pulse cluration. The sample time is the time at which electrode current is measured. It can be accurately set by using the pulse duration switches to establish first the end of the pulse at the ciesired sample point, adjusting the variable sample time control to the pulse edge, and then subsequently setting the desired duration. An alternative being considered for future versions of this system is to enter all three timing intervals digitally via a single set of panel switches, storing the desired settings in intemal latches, and allowing sample time to be established more easily and with neater stability. A marking pulse is introduced into the electrode current waveform available for display to identify the sample point. Firure 2 shows the current waveforms as well as the marking pulse produced by this system operating with an oxygen electrode. 

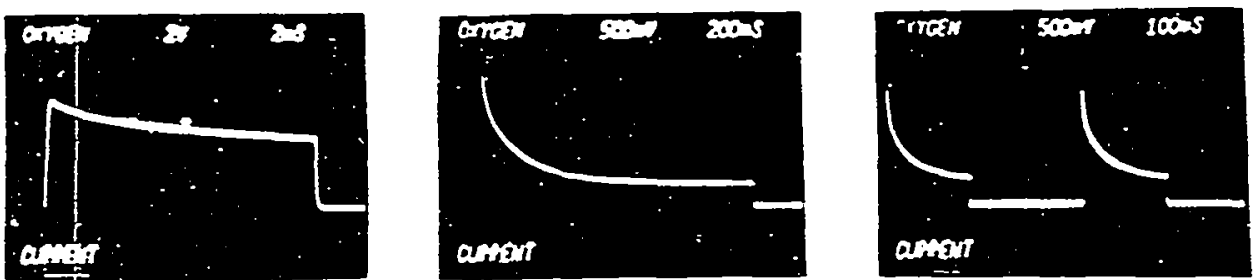

Fig. 2. Typical current waveforms ( $\mathrm{V}$ vs. time) for an oxvgen electrode. $E=-0.5 \mathrm{~V}$ vs. Ast $\lambda \mathrm{gCl}$ : marking pulse defines time of current sampling: (a) pulse duration $=15 \mathrm{~ms}$; (b) pulse duration $=1.55 \mathrm{~s} ;(\mathrm{c})$ pulse duration $=250 \mathrm{~ms}$. Pulse interval $=300 \mathrm{~ms}$.

In order to quantify the electrode current at the desired sample time, the amplified current waveform is presented to an eight-bit CMOS successiveapproximation analog-to-digital converter (ADC). A start signal is generated by the timing section to initiate the conversion at the desired sample time. The conversion time is about $7 \overline{5} \mu$ for eight-bits as used, although the converter (an Analog/Devices AD7570JD) could perform the conversion in as little as $20 \mu \mathrm{s}$ if required. The output of the converter is an eight-bit binary representation of the current amplitude at the sample time and this information is displayed on two hexadecimal LED displays. Decimal displays could also be used with additional decoding logic.

The eight-bit converter quantizes a $10 . \mathrm{V}$ reference voltage into 256 equal intervals, allowing electrode current to be determined with an accuracy of $20 \mathrm{nA}$ or better. For the present electrodes, this corresponds to an error of $20 \mu \mathrm{s} \mathrm{I}^{-1}$ or less in the measured oxygen concentration. Clock noise, thermal noise, and system stability appear consistent with the use of a 10-bit converter, which would increase the accuracy and resolution of the system by an additional factor of four while maintaining the same dymamic range. A panel switch allows the present converter to display the electrode voltage as an alternative to electrode current so that the required level can be accurately adjusted in the field.

This monitoring system has been realized by using commercial integrated circuits on a standard 30-in" wire-urap board. Power dissipation. excluding the displays (which dissipate approximately $1.2 \mathrm{WF}$ at $6 \mathrm{~V}$ ), is less than $0 . \overline{\mathrm{J}} \mathrm{W}$. The system requires $\div 6$ and $\pm 12 \mathrm{~V}$ supplies. Both a.c.- and d.c.powered versions have been realized, the latter operating from rechargeable Gel-cell battcries. Table 1 summarizes the operating characteristics of the sistem. The small size of the system makes it easily portable for field meisurements.

\section{MODER, FOR A PULSED OXYGEN ELECTRODE}

The theory of two-layer diffusion current for a membrane electrode has been clescribed in detail by Mancy et al. [2]. The steady-state current is siven by: 
$i_{\mathrm{ss}}=n F A P_{\mathrm{m}} C / b$

where $i_{\text {ss }}$ is the steady-state current (A); $n$ is the number of electron equivalents per mole of oxygen; $F$ is the Faraday constant: $A$ is the electrode area $\left(\mathrm{cm}^{2}\right) ; P_{\mathrm{m}}$ is the membrane permeability coefficient $\left(\mathrm{cm}^{2} \mathrm{~s}^{-1}\right) ; b$ is the membrane thickness $(\mathrm{cm})$; and $C$ is the bulk oxygen concentration (mol $\mathrm{cm}^{-3}$ ). Lpon application of a very short potential pulse, the current may be described by:

$i_{\mathrm{z}}=n F A\left(P_{\mathrm{m}} / \pi t\right)^{1=C}$

where $i_{\mathrm{t}}$ is the current $(A)$ at time $t(s)$. Equation (2) will be valid only if sufficient time is provided between pulses to re-equilibrate the membrane and electrolyte.

Morris and Faulkner [10] have investigated normal pulse voltammetry. using an open circuit interval and a platinum disc electrode. Equilibration of the diffusion layer during the pulse interval was inhibited by coulostatic. discharge of the double layer. It time $t=0$, a potential step was made to $E$ (see Fig. 4) where subsequent electrolysis is diffusion-limited. This potential was applied for a specific duration and the electrode was then open-circuited. Eiectrolysis proceedeci coulostatically until the potential fell to $E_{1}=$. The time it took for $E$ to fall back to $E_{1}$ : was designated as the effective pulse width. At that time the surface flu: and hence the electrolysis rate may be resauded as zero. The effective pulse width was described as follows:

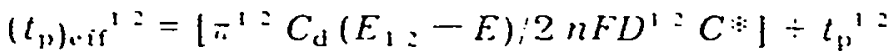

where $t_{p}$ is the pulse cluration $(s):\left(t_{p}\right)_{\text {.nf }}$ is the effective pulse width (s): $C_{a}$ is the differential double layer capacitance (farads): $E_{1}=$ is the halfWave potential $(V): E$ is the applied potential $(V): D$ is the diffusion $\cdot 0-$ efficient $\left(\mathrm{cm}^{2} \mathrm{~s}^{-1}\right): F$ is the Faraday constant: $C^{\text {: }}$ is the bulk concentration of the reactant ( $\mathrm{mol} \mathrm{cm}^{-3}$ ): and $n$ is the number of electrons. The dependence of $\left(t_{p}\right)_{\text {.rf }}$ on the solution concentration is eviclent from equ. (3). Table 2 sives the calculated values for $\left(t_{n}\right)_{\text {ei }}$ for a typical oxygen electrode at various $t_{1}$ and oxyen concentrations.

The thickness of the diffusion gradient, $x$. caused by oxyen rediction at the electrode surface can be calculated [11] for any pulse duration by

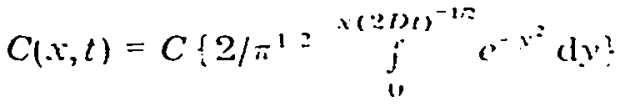

Examining the point where the bulk oxysen eoncentration is only $1^{\prime}$; different than the concentration at the electrode surface. ecin. (-1) (an be solved to grive $x(2 D t)^{-12}=1 . \mathrm{S}$. At $t=1 \mathrm{~ms}$ and $D_{f}=2.4 \times 10^{-8} \mathrm{~cm}^{2} \mathrm{~s}^{1}$. the diffusion gradient thickness is calculated as $5.6 \mu \mathrm{m}$. This is the approximate thickness of the electrolyte layer for the test electrode. At times greater than $1 \mathrm{~ms}$, it is therefore necessary to consider diffusion in the membrane and the menbrane diffusion coefficient, $D_{m}$, must be used to solve ean. (4). 
TABLE 1

Characteristics of the transient current monitoring system

\begin{tabular}{|c|c|}
\hline Electrode voltage & $\begin{array}{l}\text { Continuously adjustable } 0 \text { to } \pm 1.2 \mathrm{~V} \text {; two- or three-electrode } \\
\text { operation }\end{array}$ \\
\hline Operating modes & Single-pulse or repetitive pulse train \\
\hline Pulse duration & $1 \mathrm{~ms}$ to $2.55 \mathrm{~s}$ in two overlapping ranges \\
\hline Pulse interval & $10 \mathrm{~ms}$ to $25.5 \mathrm{~s}$ in two overlapping ranges \\
\hline Timing accuracy & Less than $0.3 \%$ error; temperature drift less than $20 \mathrm{ppm}$ \\
\hline Current amplification & 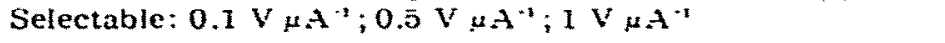 \\
\hline Sample time & $\begin{array}{l}\text { Continuously adjustable, } 5 \mathrm{~ms} \text { to } 1.5 \mathrm{~s} \text { in two overlapping } \\
\text { ranges }\end{array}$ \\
\hline Display modes & $\begin{array}{l}\text { Electrode voltage }(=2 \mathrm{mV} \text { in high gain position); electrode } \\
\text { current }(=20 \mathrm{nA} \text { in high gain position) }\end{array}$ \\
\hline Power dissipation & $\begin{array}{l}20 \mathrm{~mA} \text { at }+12 \mathrm{~V} ; 200 \mathrm{~mA} \text { at }+6 \mathrm{~V}: 1.7 \mathrm{~W} \text { total, including } \\
\text { displays }\end{array}$ \\
\hline Size & 240 in.' $(3 \times 8 \times 10$ in. $)$ \\
\hline
\end{tabular}

'The theoretical current given by eqn. (2) is based on the absence of capacitance current; however, the contribution of capacitance current to the total observed experimental current in pulsed electrode voltammetry is well known [12]. The pulse capacitance current is siven by

$i_{\mathrm{c}}=(\Delta E / R) \exp (-t / R C)$

where $i_{c}$ is the capacitance curent $(A) ; E$ is the potential change $(V): R$ is the electrode-solution resistance (ohms); $C$ is the electrode capacitance (farads); and $t$ is the pulse duration (s).

\section{RESULTS AND DISCUSSION}

The instrumentation system was originally designed to hold the electrode at $0 \mathrm{~V}$ during the pulse interval and step to $-0.8 \mathrm{~V}$ for the pulse duration. Under these conditions, very little current difference was observed for large differences in oxygen concentration. In addition to the expected cathodic faradaic current observed during the pulse duration, an anodic discharge current was also observed upon pulse termination. This condition is illustrated in Fig. 3. The anodic current arises in part from the discharge of the electrical double layer when the electrode is forced back to $0 \mathrm{~V}$. Also, when operating in the pulse mode, sufficient time must be given between pulses for the electrode to become depolarized. If this does not happen, a thick diffusion layer similar to that resulting from steady-state operation will build up, reducing electrode response.

In the light of these results, the instrument was modified to allow the electrode to float at open-circuit potential during the pulse interval as shown in Fig. 4. The open-circuit interval condition prevented the electrode double layer from completely discharging and thus reducing the charging current on the subsequent pulse. This modification greatly improved the system per- 
TABLE 2

Calculated effective pulse widths for various oxygen concentrations and pulse durations

\begin{tabular}{|c|c|c|c|c|c|c|c|}
\hline \multirow[b]{2}{*}{$\begin{array}{l}10=1 \\
\left(\mathrm{me} 1^{-1}\right)\end{array}$} & \multicolumn{3}{|l|}{$\left(t_{p}\right)_{\mathrm{e} f \mathrm{ff}}(\mathrm{ms})$} & \multirow[b]{2}{*}{$\begin{array}{l}(0: 1 \\
\left(m: l^{-1}\right)\end{array}$} & \multicolumn{3}{|l|}{$\left(t_{p}\right)_{\text {eff }}(\mathrm{ms})$} \\
\hline & $t_{p}=50 \mathrm{~ms}$ & $t_{1}=100 \mathrm{~ms}$ & $t_{p}=500 \mathrm{~ms}$ & & $t_{\mathrm{n}}=50 \mathrm{~ms}$ & $t_{1}=100 \mathrm{~ms}$ & $t_{p}=500 \mathrm{~ms}$ \\
\hline 8 & 64 & 119 & 542 & 4 & 80 & $1+0$ & 585 \\
\hline 7 & 66 & 122 & $5+8$ & 3 & 91 & 154 & 615 \\
\hline 6 & 69 & $1 \geq 5$ & 555 & 2 & iis & $18 \div$ & 677 \\
\hline 5 & 73 & 132 & 569 & 1 & 208 & 300 & $88 * 2$ \\
\hline
\end{tabular}

formance, allowing the electrode characteristics to be examined. The opencircuit potential, while variable, was found to be considerably more negative than $0 \mathrm{~V}$.

Current versus oxygen concentration for various pulse durations and an interval of $2 \mathrm{~s}$ was recorded using the instrument described. and these data are given as the open points in Fig. 5 . The sample time was just prior to pulse termination in all cases. Theoretically, the relationship between current and concentration should have been linear according to eqn. (2). but breaks were observed at $100-\mathrm{ms}$ and $150-\mathrm{ms}$ pulse durations. A series of similar experiments was done with the potential and timing controlled by the instrument
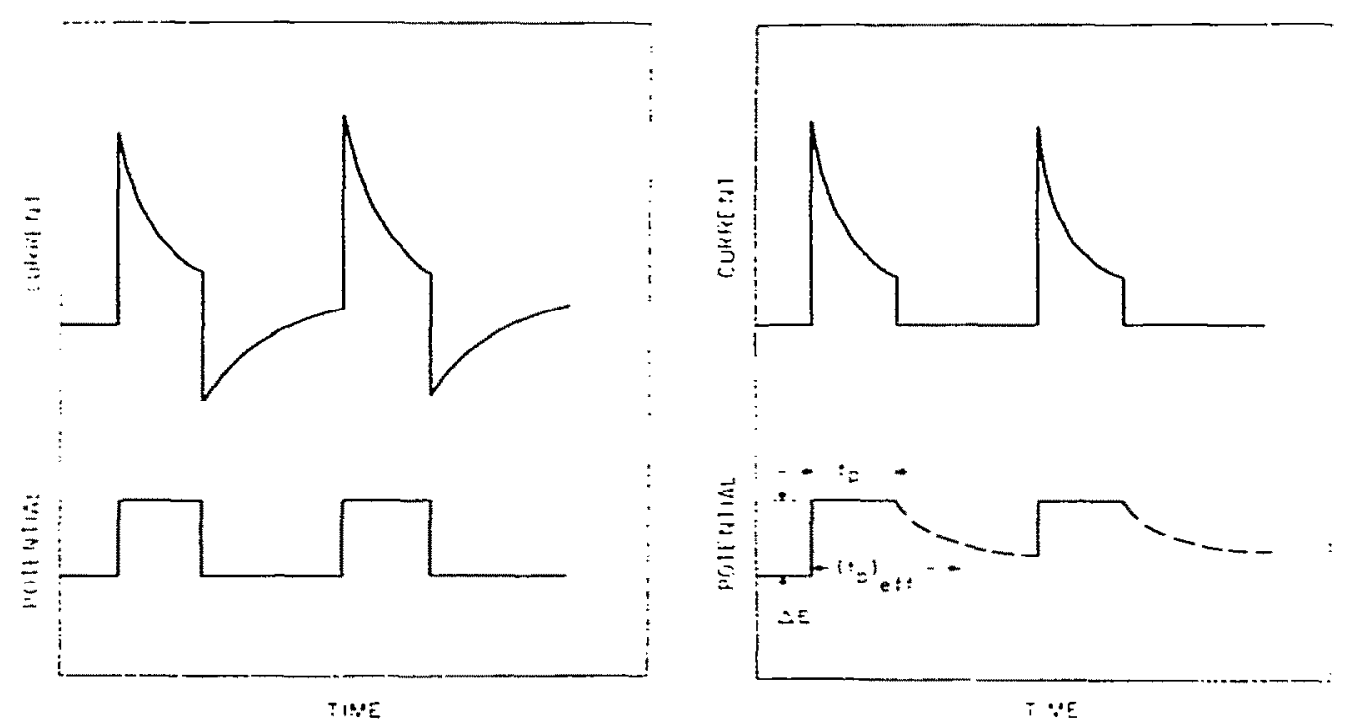

Fig. 3. Current-potential waveform for pulse potential voltammetrs with closed-circuit interval.

Fig. 4. Current--potential waveform for pulse potential voltammetry with open-circuit interval. $\triangle E$, applied potential; $t_{p}$. pulse duration; $\left(t_{p}\right)_{\text {eff }}$, effective pulse duration. 

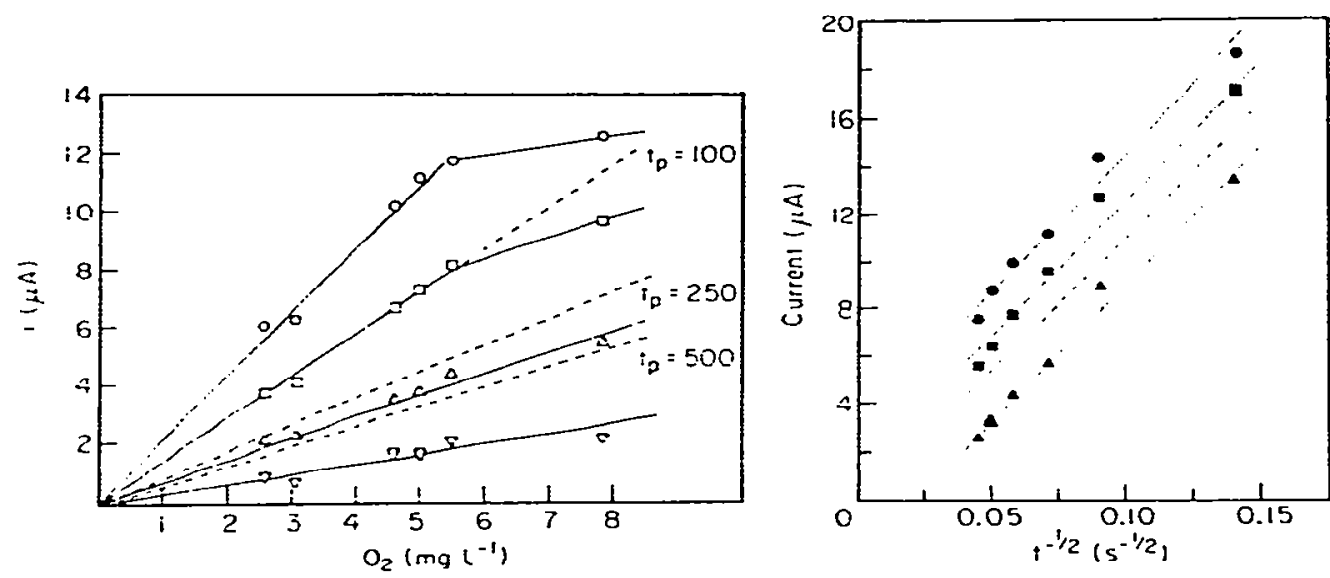

Fig. 5. Calibration curves for the pulsed oxygen electrode. Dashed lines are theoretical for indicated $t_{\mathrm{p}} ;(\because) 100 \mathrm{~ms} ;(z) 150 \mathrm{~ms} ;(\therefore) 250 \mathrm{~ms} ;(\because) 500 \mathrm{~ms}$ pulse duration; pulse interval, $5 \mathrm{~s}$.

Fig. 6. Electrode response at various pulse durations and intervals. Dashed line is theoretical current.

but with current levels determined by photographing the current at a $500-\mathrm{ms}$ pulse duration and then reading the reduction currents at shorter pulse durations from the photograph. The data exhibited the expected linear relationship at all pulse durations and the effect of pulse duration on electrode sensitivity, $\phi$, is evident from Table 3 . The sensitivity for the $50-\mathrm{ms}$ pulse is six times higher than steady state.

The breaks shown in Fig. 5 can be explained by examination of the effective pulse widths and oxygen concentrations at these times. With a $t_{\mathrm{p}}$ of $100 \mathrm{~ms}$ and an oxygen concentration of $\mathrm{S} \mathrm{mg}^{-1}$, the $\left(t_{\mathrm{p}}\right)_{\mathrm{eff}}$ obtained from Table 2 is $119 \mathrm{~ms}$. In this case the currents observed by both methods should be similar; however, as Fig. 5 shows, the currents differ experimentally by several $\mu \mathrm{A}$. By means of eqn. (5), the charging current at $100 \mathrm{~ms}$ is calculated to be $6.1 \mu \mathrm{A}\left(C=25 \mathrm{~F} \mathrm{~cm}^{-2}, R=30 \mathrm{~K}, E=-0.8 \mathrm{~V}\right)$. This might explain the difference in the two sets of data at this time and concentration. At lower oxygen concentrations the effect of $\left(t_{p}\right)_{e f f}$ is much greater (Table 2) and the observed current must be less than expected. Apparently, a point is gradually reached where the oxygen concentration is no longer sufficient to remove $E$ to $E_{1,2}$ before the subsequent pulse. With a $t_{p}$ of $500 \mathrm{~ms}$ and an oxygen concentration of $8 \mathrm{mg} \mathrm{l}^{-1},\left(t_{\mathrm{p}}\right)_{\text {erf }}$ is $542 \mathrm{~ms}$ and the two sets of data

\section{TABLE 3}

Effect of pulse duration on the pulsed voltammetric membrane oxygen electrode for a pulse interval of $2 \mathrm{~s}$

\begin{tabular}{lcccccl}
\hline Pulse duration (ms) & 50 & 100 & 150 & 250 & 500 & ss \\
$\vdots\left(\mu \mathrm{A} \mathrm{mg}^{-1} \mathrm{l}\right)$ & 1.51 & 1.09 & 0.81 & 0.66 & 0.34 & 0.25 \\
\hline
\end{tabular}


should again be similar; in this case, they are, because the charging current is negligible. At the same $t_{\mathrm{p}}$ but with an oxygen concentration of only $1 \mathrm{mg}$ $1^{-1},\left(t_{\mathrm{p}}\right)_{\text {eff }}$ is about $1.5 t_{\mathrm{p}}$; however, the difference in current at this pulse time is also negligible.

Data obtained by applying a 500-ms pulse duration and sampling the current at shorter times were taken for different oxygen concentrations at pulse intervals of 3 and $5 \mathrm{~s}$. The theoretical current for an oxygen concentration of $8 \mathrm{mg} \mathrm{I}^{-1}$ at different pulse durations was calculated from eqn. (2) and is plotted as the dashed line in Fig. 6 versus the reciprocal square root of the pulse duration. The experimental currents were also plotted for the different time intervals. The agreement between the slopes is excellent. Experimental currents were higher than predicted by eqn. (2) possibly because of an error in the selection of a permeability coefficient (known to change from batch to batch) and/or the electrode area determination.

\section{Conclusions}

The transient current monitoring instrumentation system has been shown to be a very useful device for pulsed electrode characterization. It has eliminated the need for using an oscilloscope to record transient current, making it portable and suitable for field measurements. In order to achieve still greater fiexibility in investigating transient electrode phenomena. an all-CMOS microcomputer-controlled instrumentation system has also been developed. This system should allow correction for the effects of secondary parameters, such as temperature, which can also influence electrode response and will be reported in a separate paper.

The authors gratefully acknowledge the many contributions of $K$. Holloway, N. Ho, and J. C. Huang in the construction and testing of the instrumentation system. This work was supported by U.S. Envirommentid Protection Agency Grant No. R804834-01-1.

\section{REFERENCES}

I K. II. Mancy and T. Jafle, Analysis of Dissolved Oxygen in Natural and Waste Waters, U.S. Dept. HEW, Puhlic Health Service, Publ. No. 999-liP-37, April 1966.

2 K. H. Maney, D. A. Okun, and C. N. Reilly, J. Electroanal. Chem., 4 (1962) 65.

3 I. Fatt, Polarographic Oxygen Sensors, CRC Press, Cleveland, OH, 1976.

1 M. Schmid and K. H. Mancy, Schweitzerische für Hydrologie, 32 (1970) 328.

5 K. H. Mancy, in W. A. Adams (Ed.), Chemistry and Physics of Aqueous Gas Solutions, The Electrochemical Society, Princeton, NJ, 1976.

6 M. Lilley, J. Story, and R. Raible, J. Electroanal. Chem., 23 (1969) 425.

7 J. $k$. Fowler and $K$. B. Oldham, in W. A. Adams (Ed.), Chemistry and Physies of Aqueous Gas Solutions, The Electrochenical Society, Princeton, NJ, 1976.

S R. Adams, Electrochemistry at Solid Eleetrodes, N. Dekker, New York, 1060.

9 Standard Method for the Examination of Water and Wastewater, 1tih edn., Am. Public Health Assoc., 1976.

10 J. L. Morris and L. R. Faulkner, Anal. Chem., 49 (1977) 489.

$11 \mathrm{~J}$. Crank, The Mathematics of Diffusion, Clarendon Press, Oxford, 1956.

12 P. Delahay, New Instrumental Methods in Flectrochemistry, Interscience, New York, 1954. 